\title{
Expression and localization of two gonadotropin receptors in gonads of the yellowtail clownfish, amphiprion clarkii
}

\begin{abstract}
Two gonadotropins ( $\mathrm{GtH}), \mathrm{FSH}$ and $\mathrm{LH}$, play central roles in vertebrate reproduction. They act through specific gonadotropin receptors (GtHr), Fshr and $\mathrm{Lhr}$, respectively, to stimulate testicular and ovarian functions. To investigate the action of $\mathrm{GtH}$ in clownfish, we examined gonadal FSHR and LHR mRNA expression levels. Levels of LHr mRNA were similar in the ambisexual gonad of the male and the ovary of the female. In contrast, Fshr expression was higher in the male than in the female. Additionally, in situ hybridization identified the cellular location of the receptor transcripts. In the ambisexual gonads of the male, both receptor gene transcripts were evident in active testicular tissue, and they were not evident in non-active ovarian tissue. These findings support the hypothesis that clownfish modulate the activity of and response to GtHs by controlling the expression of the GtH receptors.
\end{abstract}

Keywords: Clownfish, Gonadotropin, Gonadotropin Receptor, FSH, LH, Gonad
Volume 5 Issue 3 - 2017

\author{
Yasuhisa Kobayashi,' Ryo Nozu, ${ }^{2}$ Masaru \\ Nakamura $^{2}$ \\ 'Department of Fisheries, Kindai University, Japan \\ ${ }^{2}$ Zoological Laboratory, Okinawa Churashima Research Center, \\ Japan
}

Correspondence: Yasuhisa Kobayashi, Laboratory for Aquatic Biology, Department of Fisheries, Faculty of Agriculture, Kindai University, Japan, Tel +8I-742-43-I5II,

Email yasuhisa@nara.kindai.ac.jp

Received: February 08, 2017| Published: March 08, 2017
Abbreviations: GTH, Gonadotropin; FSH, Follicular Stimulating Hormone; LH, Luteinizing Hormone; FSHR, Follicular Stimulating Hormone Receptor; LHR, Luteinizing Hormone Receptor

\section{Introduction}

Clownfish (e.g., Amphiprion species) are common inhabitants of tropical coral reefs, where they avoid predators by living among the stinging tentacles of sea anemones. Each clownfish group associated with an anemone consists of one breeding pair and between zero and four non-breeders. ${ }^{1}$ A size-dominance hierarchy characterizes each group, with the female as the largest and dominant member, the male as the second largest member, and any non-breeders as smaller members of the group. ${ }^{2}$ The disappearance or death of the female leads to protandrous (male to female) sex change of the male fish, which in becoming female also becomes dominant. ${ }^{3}$ We are interested in the physiological and endocrinological mechanisms of sex change in clownfish.

Histological analysis of the gonads of clownfish revealed that males and non-breeders possess ambisexual gonads with co-existing mature testicular and immature ovarian tissues, whereas gonads of females contain only ovarian tissue..$^{4,5}$ During sex change, the ovarian tissues develop and the testicular tissues regress in ambisexual gonads. ${ }^{6}$ The mechanisms of this process have been extensively studied. As in other sex-changing species, ${ }^{7,8}$ gonadal sex steroid hormones, especially estrogen, are the key regulators of sex change in clownfish., ${ }^{4-11}$ The upstream mechanisms controlling the production and activity of gonadal steroid hormones during sex change, however, are largely unknown.

As in other vertebrates, gonadal steroidogenesis in teleosts is largely controlled by two pituitary-produced gonadotropins (GtH), follicular stimulating hormone (Fsh) and luteinizing hormone (Lh). ${ }^{12}$ The activities of these GtHs are mediated by their specific receptors (GtHr), Fsh receptor (Fshr) and Lh receptor (Lhr), which function at the surface of target cells in the gonads. ${ }^{13}$ Fsh is thought to play a significant role during puberty and gametogenesis, whereas Lh is primarily involved in final maturation of the gametes in both sexes. ${ }^{12}$ There has been renewed interest recently in deciphering the roles of GtHs and their receptors in sex change mediated by gonadal steroid hormones. For example, sexually dimorphic expression of the subunits of $\mathrm{GtH}$ have been reported in various sex-changing fishes. ${ }^{14,15}$ Furthermore, treatment of groupers with Fsh induces protogynous sex change in female grouper. ${ }^{16}$ These results indicate that gonadal sex change is regulated by GtH via the pituitary-gonadal axis. The current study focused on the expression of GtH receptors in the gonads of clownfish. The yellowtail clownfish, Amphiprion clarkii, was used as the experimental model in this study, because this species is one of the most abundant and larger species in Okinawa, Japan. ${ }^{2}$ Reporting the expression profiles of $A$. clarkii $\mathrm{GtHr}$ genes in the ambisexual gonads of males and the ovary of females using real-time RT-PCR assays. We also localized the mRNA transcripts of each receptor in the gonads by in situ hybridization.

\section{Materials and methods}

\section{Experimental fish}

Seven pairs of adult breeding male and female yellowtail clownfish were purchased from a fisherman of Nakijin Village, Okinawa Japan. Fish were anesthetized with 2-phenoxyethanol (Wako chemicals, Osaka, Japan) before sampling. After measurement of total length and body weight, the fish were sacrificed by decapitation. Brain, gill, heart, spleen, liver, intestine and most of the gonadal tissue were removed by dissection and stored in RNA later reagent (Ambion, TX, USA) at $-30 \circ \mathrm{C}$ until RNA extraction. For in situ hybridizations, the remaining gonadal tissue was fixed in freshly prepared $4 \%$ paraformaldehyde (PFA) in $0.1 \mathrm{M}$ phosphate buffer overnight at $40 \mathrm{C}$.

\section{RNA extraction and cloning of GtHr cDNAs}

Total RNA was extracted using the RN easy mini kit with RNase free DNase kit (Qiagen Inc., Valencia, CA) according to the manufacturer's protocols. RNA concentrations were measured using a NanoDrop ND-1000 spectrophotometer (NanoDrop Technologies, DE). RNA samples were used for cloning and quantitative RT-PCR. 
Two set of degenerate $(\mathrm{dn})$ primers, which are conserved nucleotide regions for $\mathrm{Fshr}$ and $\mathrm{Lhr}$ are designed respectively. (dn Fshr forward (Fw): 5'-gatgmettyaaccectgtgargayatcatg-3', dn Fshr reverse (Rev): 5'-gaaggggttggmgcaygarttgatkgggta-3', dn Lhr Fw: 5'-gcngaygmbttyaayccbtgygarg-3', dn Lhr Rev: 5'-genganabrgcrwaraangaratvggngecatrca-3'.) First-strand cDNA synthesized from the total ovarian RNA $(1.2 \mu \mathrm{g})$ by SuperScript II RT-transcriptase (Invitrogen, San Diego)was subjected to 30 cycles of PCR amplification. The $20 \mu 1$ reaction mixture of PCR contained $2 \mu 1$ cDNA template, $1 \mu 1$ each degenerate primer $(20 \mu \mathrm{M}), 2 \mu 1$ 10xPCR buffer, $2 \mu 12.5 \mathrm{mM}$ dNTP, and $1 \mathrm{U}(0.2 \mu \mathrm{l})$ ExTaq (Takara Co. Ltd., Shiga, Japan). PCR conditions were 30 cycles of $30 \mathrm{sec}$ at $94 \mathrm{oC}, 30$ $\mathrm{sec}$ at $50 \mathrm{oC}$, and $30 \mathrm{sec}$ at $72 \mathrm{oC}$. The PCR amplicons obtained for Fshr (822 bp) and Lhr (736 bp) were sub-cloned into pGEM-T-Easy (Promega, Madison, WI) vector and sequenced. Sequence analysis showed these fragments were teleost Fshr and Lhr gene. GenBank accession numbers for cDNA sequences are as follows: Fshr, AB564291; Lhr, AB564292.

\section{Real-time RT-PCR of clownfish gonadotropin receptors transcript}

The abundances of two GtHrs transcript in the gonads of male and female and various tissues were determined by real-time RTPCR assay. Total RNAs (500 ng) of sample were reverse transcribed by Omni Script (Qiagen) with random hexamers primer. Real-time RT-PCR was carried out on a Mini Opticon (BioRad, Hercules, CA, USA). Reactions were performed in $12 \mu \mathrm{l}$ solution, with $200 \mathrm{nM}$ of each primers, $2 \mu \mathrm{l}$ of $5 \mathrm{ng}$ cDNA samples and the SYBER-green master mix (KAPA SYBER FAST qPCR kit, KAPA bio-systems, Boston, Massachusetts, USA) according to the manufacture's instructions. Assays (in triplicate) were repeated at least twice with the constitutive elongation factor $1 \alpha$ (efla) as a normalizing control. Primer pairs were designed using Primer3 software. ${ }^{15}$ The data relative changes in mRNA expression were determined using $2^{-\triangle \Delta C t}$ method. ${ }^{16}$ The following primers were applied for realtime RT-PCR assay: Fshr Fw: 5'-tctggatcatctccatcctg-3', Fshr Rev: 5'-acatgaggaaacgaggaacg-3', Lhr Fw: 5'-ctgtttagggatggggatg-3', Lhr Rev:5'-ccacattgaagagcaggatg-3', eflaFw:5'-acgtgtccgtcaaggaaatc-3', efla Rev: 5'-acctgggcattgaagttgtc-3'.

\section{In situ hybridization for two gonadotropin receptors in the clownfish gonads}

To identify the cellular locations of Fshr and Lhr mRNA, gonadal sections $(6 \mu \mathrm{m})$ fixed in PFA were hybridized with DIG-labeled clownfish GtHr cRNA probes overnight at $550 \mathrm{o}$. Both sense and antisense probes for each receptor gene were labeled using standard transcription reactions and a DIG-labeling nucleotide mix (Boehringer Mannheim, Tokyo, Japan). Hybridization signals were detected with alkaline phosphatase-conjugated antibody. Sections were incubated for 2 hours at room temperature with DIG antibody. After incubation, sections were incubated with NBT/BCIP substrate for the detection of alkaline phosphate activity.

\section{Results}

\section{Quantification of gonadotropin receptor mRNAs in clownfish gonads}

To understand the involvement of the two GtHrs in clownfish sex change, GtHr transcript levels in the ambisexual gonads of males and in the ovaries of females were investigated (Figure 1). Both receptor genes were expressed in the ovary. Two-fold higher expression of Fshr was evident in the ambisexual gonad of male compared to that in the ovary of the female (Figure 1). In contrast, the level of Lhr transcript did not differ between the ambisexual gonad and the ovary (Figure 1).

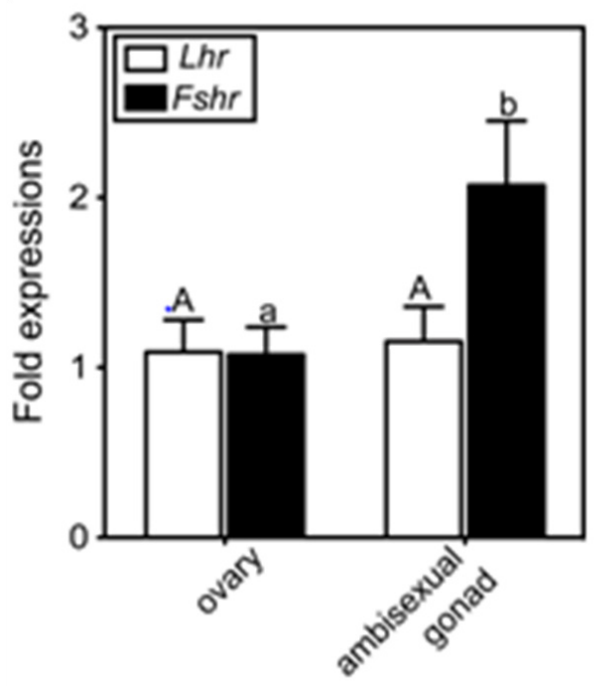

Figure I Real-time quantitative RT-PCR analysis of gonadotropin receptor mRNA levels in the ovary (female) and the ambisexual gonad (male) of the clownfish, A. clarkii. The values were calibrated with an internal control (efla).

The abundance of each transcript is expressed relative to that in the ovary. The number of each samples is 7 . The data shown are \pm SEM. Different letters for each genes indicate statistically significant differences $(\mathrm{P}<0.05$; Tukey multiple comparison test $)$.

\section{Tissue distribution of Fshr and Lhr transcripts in clownfish}

To examine the tissue distribution of Fshr and Lhr transcripts, real-time RT-PCR assays were carried out using total RNA isolated from selected tissues. In addition to gonadal tissues, transcripts of Lhr were present, and at different levels, in the brain, heart and intestine, but were not detected in the gill, spleen or liver (Figure 2). The Lhr transcript level in the brain, the highest level of the examined nonreproductive tissues, was one-tenth that in the ovary (data not shown). The expression of Fshr was detected in the brain and the spleen. Similarly, Fshr transcripts in the ovary were significant higher than in the spleen, which had the highest level of expression of the examined non-reproductive tissues (data not shown). Sexual differences in the two receptor transcripts were not observed in this assay.

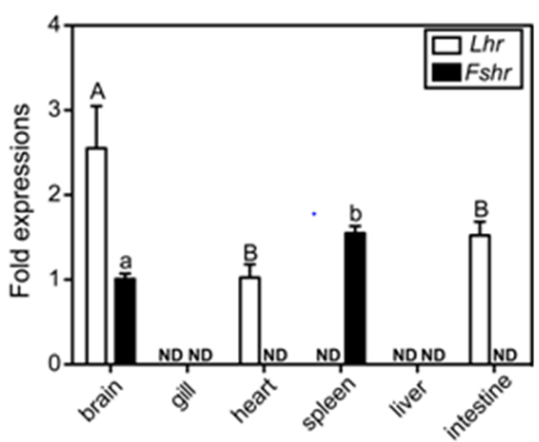

Figure 2 Tissue distributions of clownfish GtHr transcripts. The values were calibrated with an internal control (efla) and are expressed as fold changes in abundance relative to transcript levels in the brain (Fshr) and heart (Lhr), which were the lowest detectable expression levels, respectively. Data shown are \pm SEM. ND indicates not detected. 
The data shown are \pm SEM. Different letters for each genes indicate statistically significant differences $(\mathrm{P}<0.05$; Tukey-Kramer multiple comparison test).

\section{Cellular localizations of GtHr mRNAs in the gonadal tissues}

The Fshr mRNA was found primarily in granulosa cells of the ovarian follicle of the female (Figure 3A). In vitellogenic follicles, signals of Lhr were seen in the thecal cells (Figure 3B). In the testicular tissues of male ambisexual gonad, Fshr signals were detected in Sertoli cells (Figure 3C) and Lhr signals were found in the Leydig cells (Figure 3D). In contrast to the ovary of females, neither Fshr nor Lhr gene signals were detected in either the granulosa or the thecal cells of ovarian tissue in the ambisexual gonad of male (Figure $3 \mathrm{E} \& \mathrm{~F})$. No signal was obtained for either of the control sense probes for Fshr and Lhr (Figure 3a-f).

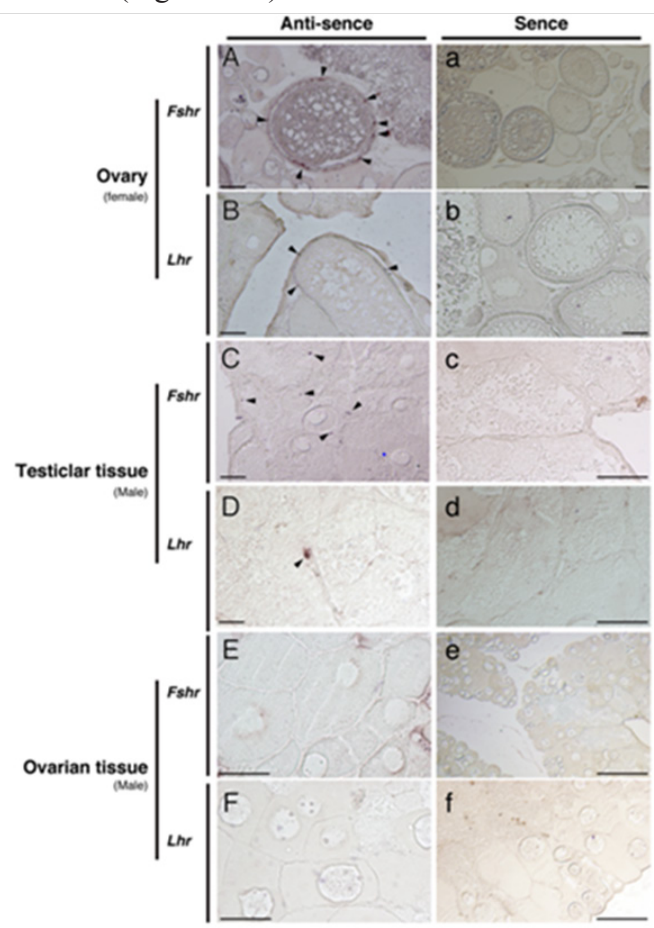

Figure 3 In situ hybridization detection of the presence of Fshr (A, C and E) and $\operatorname{Lhr}(\mathrm{B}, \mathrm{D}$ and F) transcripts in the clownfish ovary (female) and ambisexual gonad (testicular and ovarian tissues, male). Arrowheads indicate positive signals. Controls using sense probes for both genes are shown (a-f). Bars indicate $50 \mu \mathrm{m}$.

\section{Discussion}

In this study, we investigated the expression patterns of two GtHrs in various clownfish tissues using real-time RT-PCR. Additionally, the current research results of in situ hybridization analysis identified the cellular locations of both receptor gene transcripts within clownfish gonadal tissues. As reported for mammals and other teleosts, ${ }^{17}$ clownfish Lhr mRNA is present in Leydig cells of the testicular tissue and in the cal cells of the ovarian follicle, whereas Fshr expression is restricted to Sertoli cells and granulosa cells of the testicular tissues and ovary, respectively. The main functions of Sertoli and granulosa cells are in the development of germ cells, whereas Leydig and the cal cells support gamete maturation. ${ }^{18,19}$ Therefore, our results, which document the levels and locations of the two different receptor gene transcripts, indicate that in clownfish, Fsh controls puberty of the gonad and germ cell renewal, whereas Lh controls final gamete maturation in both sexes, as noted in other vertebrates.

Expression of clownfish Fshr and Lhr genes was detected, using real-time RT-PCR assays, in the ambisexual gonad and the ovary as anticipated. The relative expression of Fshr was two-fold higher in the ambisexual gonad than in the ovary, whereas Lhr expression exhibited no significant difference between the sexes. Our recent studies of the honeycomb grouper, Epinephelusmerra, which is a protogynous hermaphrodite, also noted a high level of expression of Fsh and Fshr in males, ${ }^{14,20}$ suggesting that spermatogenesis is controlled primarily by Fsh, not $\mathrm{Lh}$, in the grouper. It is therefore possible that in clownfish as well, Fsh may have a greater effect over spermatogenesis than over oogenesis. We also detected lower transcripts of both receptor genes in clownfish extra-gonadal tissues. As seen in other fish ${ }^{21-23}$ and tetrapods, ${ }^{24}$ expression of both receptor genes has been observed non-reproductive tissues. Since these transcript levels were low, the expression of these genes was not detected here by in situ hybridization in these non-reproductive tissues (Data not shown). Therefore, the possible physiological significance of the receptor genes in non-reproductive tissues is not well understood.

As noted above, male clownfish possess ambisexual gonads with co-existing active testicular tissues and non-active ovarian tissues. ${ }^{6,25}$ An important unanswered question has been how the ovarian tissues of the ambisexual gonad remain immature despite the presence of GtHs secreted via the circulatory system to both tissues. Here we demonstrate by in situ hybridization that expression of the two GtHr genes is localized only to the testicular tissues and not to the ovarian tissues. These results suggest that clownfish modulate the activity of and the response to GtHs by controlling the expression of the GtH receptors. Consistent with this view, we recently reported that the expression of $\mathrm{GtH}$ receptors in active gonads of the bi-directional sex-changing gobiid fish, Trimmaokinawae, is regulated and that the tissue locations where $\mathrm{GtHr}$ is expressed shift rapidly, in less than one day, after the initiation of sex change. ${ }^{26}$ We therefore surmise that in clownfish as well the location of GtHr expression shifts upon initiation of sex change. In the near future, we plan to clarify the changes in the location and levels of expression of both receptor genes during sex change in A. clarkii.

\section{Conclusion}

In conclusion, the results presented here demonstrate the expression and localization of GtH receptor gene transcripts in the gonads of the yellowtail clownfish, A. clarkii. Further studies of how receptor transcript levels vary during sex change should help us understand not only the physiological significance of GtHs but also the shifting patterns of $\mathrm{GtH}$ receptor expression in gonads undergoing sex change.

\section{Acknowledgements}

This work was supported by JSPS Kakenhi Grand Number 16K07873.

\section{Conflicts of interest}

None.

\section{References}

1. Elliott JK, Mariscal RN. Coexistence of nine anemonefish species: differential host and habitat utilization, size and recruitment. Mar Biol. 2001;138(1):23-36. 
2. Hattori A. Social and mating systems of the protandrous anemonefish Amphiprion perideraion under the influence of a larger congener. Austral Ecol. 2000;25(2):187-192.

3. Fricke H, Fricke S. Monogamy and sex change by aggressive dominance in coral reef fish. Nature. 1977;266(5605):830-832.

4. Godwin JR, Thomas P. Sex change and steroid profiles in the protandrous anemonefish Amphiprion melanopus (Pomacentridae, Teleostei). Gen Comp Endocrinol. 1993;91(2):144-157.

5. Nakamura M, Mariko T, and Nagahama Y. Ultrastructure and in vitro steroidogenesis of the gonads in the protandrous clownfish Amphiprion frenatus. Japan Journal of Ichthyology. 1994;41:47-56.

6. Godwin J. Historical aspects of protandrous sex change in the anemonefish Amphiprion melanopus (Pomacentridae, Teleostei). Journal of Zoology. 1994;232(2):199-213.

7. Nakamura M, Kobayashi Y, Miura S, et al. Sex change in coral reef fish. Fish Physiol Biochem. 2005;31(2-3): 117-122.

8. Kobayashi Y, Nagahama Y, Nakamura, M. Diversity and plasticity of sex determination and differentiation in fishes. Sex Dev. 2013;7(13):115-125.

9. Kobayashi Y, Horiguchi R, Miura S, et al. Sex- and tissue-specific expression of P450 aromatase (cyp19a1a) in the yellowtail clownfish, Amphiprion clarkii. Comp Biochem Phys A. 2010;155(2):237-244.

10. Nakamura M, Miura S, Nozu R, et al. Opposite-directional sex change in functional female protandrous anemonefish, Amphiprion clarkii: effect of aromatase inhibitor on the ovarian tissue. Zoological Lett 1 . $2015 ; 30$.

11. Themmen APN, Huhtaniemi IT. Mutations of gonadotropins and gonadotropin receptors: elucidating the physiology and pathophysiology of pituitary-gonadal function. Endocr Rev. 2000;21(5):551-583.

12. Ohta K, Mine T, Yamaguchi A, et al. Sexually dimorphic expression of pituitary glycoprotein hormones in a sex-changing fish (Pseudolabrus sieboldi). J Exp Zool A Ecol Genet Physiol. 2008;309(9):534-541.

13. Lee YH, Du JL, Yueh WS, et al. Sex change in the protandrous black porgy, Acanthopagrus schlegeli: a review in gonadal development, estradiol, estrogen receptor, aromatase activity and gonadotropin. $J$ Exp Zool. 2001;290(7):715-726.

14. Kobayashi Y, Alam MA, Horiguchi R, et al. Sexually Dimorphic Expression of Gonadotropin Subunits in the Pituitary of Protogynous Honeycomb Grouper (Epinephelus merra): Evidence That FollicleStimulating Hormone (FSH) Induces Gonadal Sex Change. Biol Reprod. 2010;82(6):1030-1036.
15. Rozen S, Skaletsky H. Primer3 on the WWW for general users and for biologist programmers. Methods Mol Biol. 2000;132:365-386.

16. Livak KJ, Schmittgen TD. Analysis of relative gene expression data using real-time quantitative PCR and the 2(-Delta Delta C(T)) Method. Methods. 2001;25(4):402-408.

17. Levavi-Sivan B, Bogerd J, Mananos EL, et al. Perspectives on fish gonadotropins and their receptors. Gen Comp Endocrinol. 2010;165(3):412-437.

18. Lubzens E, Young G, Bobe J, et al. Oogenesis in teleosts: how eggs are formed. Gen Comp Endocrinol. 2010;165(3):367-389.

19. Schulz RW, de Franca LR, Lareyre JJ, et al. Spermatogenesis in fish. Gen Comp Endocrinol. 2010;165(3):390-411.

20. Alam MA, Kobayashi Y, Hirai T, et al. Isolation, characterization and expression analyses of FSH receptor in protogynous grouper. Comp Biochem Physiol A Mol Integr Physiol. 2010;156(3):364-371.

21. Oba Y, Hirai T, Yoshiura Y, et al. Cloning, functional characterization, and expression of a gonadotropin receptor cDNA in the ovary and testis of amago salmon (Oncorhynchus rhodurus). Biochem Biophys Res Commun. 1999;263(2):584-590.

22. Kwok HF, So WK, Wang Y, et al. Zebrafish gonadotropins and their receptors: I. Cloning and characterization of zebrafish folliclestimulating hormone and luteinizing hormone receptors-evidence for their distinct functions in follicle development. Biol Reprod. 2005;72(6):1370-1381.

23. Maugars G, Schmitz M. Molecular cloning and characterization of FSH and LH receptors in Atlantic salmon (Salmo salar L.). Gen Comp Endocrinol. 2006;149(1):108-117.

24. Ascoli M, Fanelli F, Segaloff DL. The lutropin/choriogonadotropin receptor, a 2002 perspective. Endocr Rev. 2002;23(2):141-174.

25. Nakamura M, Hourigan TF, Yamauchi $\mathrm{K}$, et al. Histological and ultrastructural evidence for the role of gonadal steroid hormones in sex change in the protogynous wrasse Thalassoma duperrey. Environmental Biology of Fishes. 1988;24(2):117-136.

26. Kobayashi Y, Nakamura M, Sunobe T, et al. Sex change in the gobiid fish is mediated through rapid switching of gonadotropin receptors from ovarian to testicular portion or vice versa. Endocrinology. 2009; 150(3):1503-1511. 